\title{
Kolon polipleri: Lokalizasyon, histoloji, boyut - beş yıllık kolonoskopik değerlendirme
}

\author{
Colon polyps localization, histology, and size - five years of colonoscopic research
}

Yasin ŞAHINTÜRK ${ }^{1}$, Ayhan Hilmi ÇEKIN ${ }^{2}$

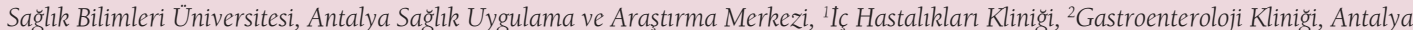

\begin{abstract}
Giriş ve Amaç: Kolon polipleri konusunda hasta sayısı fazla olan bir çalışma yaparak konu hakkındaki epidemiyolojik verilere prevalans, histoloji, boyut ve lokalizasyon konusunda katkı yapmak. Gereç ve Yöntem: 2012-2017 yilları arasinda kolonoskopi yapilan 2512 hasta kolon polip prevalansi, histolojisi (hiperplastik, adenomatöz, serrated), boyutu $(<1 \mathrm{~cm}$ ve $>1 \mathrm{~cm}$ ) ve lokalizasyonuna (rektum, sigmoid kolon, inen kolon, transvers kolon, çıkan kolon, çekum) göre değerlendirildi. Bulgular: Çalışmaya alınan 2.512 hastanin 876'sinda $(\% 34,9)$ polip saptand1. 104'ünde $(\% 11,9)$ hiperplastik polip saptanirken, $10(\% 1,1)$ hastada serrated polip, $650(\% 74,3)$ hastada adenomatöz polip saptandı. Saptanan poliplerin $696(\% 79,4)$ tanesi 1 cm'den küçükken, $180(\% 20,6)$ tanesi 1 cm'den büyüktü. Yerleşim bölgeleri incelendiğinde en sık rektal bölgede $323(\% 36,9)$ polipler saptanırken proksimal kolon kesimlerinde polip görülme yüzdesi azalmaktaydı. Yaş arttıkça polip görülme sıklığı, adenamatöz histoloji varlığı ve polip boyutu artmaktaydı. Erkeklerde polip saptanma yüzdesi, kadınlarda ise $>1 \mathrm{~cm}$ polip saptanma sıklığı daha fazlaydı. Sonuç: Çalıșmamız literatüre göre yüksek hasta sayısı içermesi nedeniyle değerli sonuçlar içermektedir. Epidemiyolojik açıdan literatür verilerine göre saptadığımız yüksek polip prevalansı tarama programlarında daha dikkatli davranmamız gerektiğini düşündürmüştür.
\end{abstract}

Anahtar kelimeler: ?Kolon polip, prevalans, histoloji, lokalizasyon, boyut

\section{GIIRIS}

Mukoza veya submukoza epitelinden barsak lümeni içine doğru çıkıntı yapan yapılara kolon polipleri denir (1). Kolon polipleri malignite öncüsü olabilecekleri için bulundukları lokalizasyon, boyutları ve histolojik tiplendirmesi son derece önemlidir (2). Saptandıklarında eksize edilmeleri gelişebilecek malignitenin önüne geçilmesi ve histopatolojik değerlendirme açısından kolon poliplerinin yönetiminde en önemli basamaktır (3).

Kolon polipleri non-neoplastik ve neoplastik olarak iki gruba ayrılmaktadır. Non-neoplastik polipler ağırlıklı olarak hiperplastik polipleri içermekte olup, neoplastik poliplerde ise büyük bir kısmı adenomatöz polipler oluşturmaktadır (4). Adenomatöz polipler ise kendi içinde tübüler-tübülövillöz-villöz olarak ayrılmaktadır. Görülme sıklı̆̆ tübüler (\%65-80), tübülovillöz (\%10-25) ve villöz (\%5-15) adenom$\operatorname{dur}(4)$
Background and Aims: We conducted a study with a large number of patients to contribute to the epidemiological information in the literature on prevalence, histology, size, and localization of colon polyps. Materials and Methods: Between 2012 and 2017, 2.512 patients underwent colonoscopy to determine colon polyp prevalence, histology (hyperplastic, adenomatous, and serrated), size $(<1 \mathrm{~cm}$ and $>1 \mathrm{~cm})$, and localization (rectum, sigmoid colon, descending colon, and transverse colon). Results: Polyps were detected in $876(34,9 \%)$ of 2.512 patients who were included in the study. Hyperplastic polyps were detected in $104(11,9 \%)$ patients, serrated polyps in $10(1,1 \%)$ patients, and adenomatous polyps in $650(74.3 \%)$ patients. Most (696, 79,4\%) detected polyps were smaller than $1 \mathrm{~cm}$, but 180 (20,6\%) were larger than $1 \mathrm{~cm}$. According to the localization of polyps, 323 (36,9\%) were detected in the rectal region, whereas the percentage of polyps in the proximal colon segments decreased. As age increased, the incidence of polyps, adenomatous histology, and polyps increased. When compared with that in females, the percentage of polyp prevalence was higher in males. However, females had a higher rate of polyps larger than $1 \mathrm{~cm}$ when compared with males. Conclusion: Our study has meaningful results due to the high number of patients. In particular, the high prevalence of polyps we detected according to data reported in the literature should encourage all clinicians to establish a carefully executed screening program.

Key words: Colon polyp, prevalence, histology, localization, size

Normal kolon mukozasında hücre çoğalması ve değişimi sürekli olarak devam eder ve her 3-6 günde mukoza yüzeyi yenilenir. Özellikle proliferatif çoğalma kriptin bazal 1/3'de yoğun olarak devam eder. Bazalda büyüme ve farklılaşmaya başlayan hücreler sonunda genellikle goblet hücresi olur (5). Hiperplastik poliplerde farklılaşmada gecikme ve apoptozisde azalma görülmezken; adenomatöz poliplerde ise tam tersi mekanizma nedeniyle artan proliferasyon ile beraber artan sayıda hücreler kriptlere doğru yayılır (6).

Boyut ve malignite arasındaki ilişkiye bakıldığında ise; kılavuzlar polip boyutu için $10 \mathrm{~mm}$ sınırını malignite gelişmesi açısından sınır kabul etmekte ve hastaların kolonoskopi takipleri polip boyutuna göre değişiklik göstermektedir. Polip boyut, sayı ve histolojiyi içine alan kolon kanseri gelişimi açısindan risk sinıflamasına göre hastalar; düşük risk 1-2 adenom $<10$ mm, orta risk 3-4 küçük adenom veya $>10 \mathrm{~mm}$ tek adenom ve yüksek risk $>5$ küçük adenom veya $>3$ adenom ve en az biri >10 mm şeklinde sınıflanmıştır (5). 
Tablo 1. Hastalarda polip saptama durumu

$\begin{array}{lccc}\text { Polip } & \text { Sayı (n), (\%) } & \text { Erkek (n), (\%) } & \text { Kadın (n), (\%) } \\ \text { Yok } & 1.640(65,1) & 655(61) & 985(68) \\ \text { Var } & 876(34,9) & 408(39) & 468(32) \\ \text { Toplam } & 2.516(100) & 1.063(100) & 1.453(100)\end{array}$

Kolorektal polipler kolorektal kanser dağılımına paralel olarak distal kolon ve rektumda daha sık görülürler. Küçük polipler için belirli bir lokalizasyon söylemek mümkün değilken, büyük polipler daha sık distal kolon yerleşimlidir $(7,8)$. Kolon polipleri anatomik olarak \%40 oranında sağ kolon yerleşimli iken (çekum, çıkan kolon, hepatik fleksura, transvers kolon) \%31 sol kolon yerleşimli (splenik fleksura, inen kolon ve sigmoid kolon) ve \%29 oranında rektum yerleşimlidir. 1980'den bu yana kolon kanserleri sol kolondan sağa doğru değişim göstermektedir (8).

Bu çalışmamızda kliniğimizde yapılan kolonoskopi sonuçlarinda polip prevalansı, boyutu, histolojisi ve lokalizasyonu ile ilgili sonuçları epidemiyolojik olarak dökümante etmeyi amaçladık.

\section{GEREÇ ve YÖNTEM}

Araştırma popülasyonunu Antalya Eğitim ve Araştırma Hastanesi Gastroenteroloji kliniğinde 2012-2017 yllları arasında kolonoskopi yapılan 2.512 hasta oluşturmaktadır. Hastalar daha önce polip saptanması, kolon kanseri öyküsü, inflamatuvar barsak hastalığı tanısı olması ve geçirilmiş kolon operasyonu öyküsü olması durumunda araştırma popülasyonundan çıkarılmıştır. Polip saptanan 876 hasta poliplerin patolojik sınıflamasına göre (hiperplastik, adenomatöz, serrated), boyutlarına göre $<1 \mathrm{~cm}$ ve $>1 \mathrm{~cm}$ ve lokalizasyonuna göre (rektum, sigmoid kolon, inen kolon, transvers kolon, çıkan kolon, çekum) olarak sınıflanmıştır.

Tanımlayıcı istatistikler frekans, yüzde, ortalama (mean), standart sapma (SD) değerleri ile sunulmuştur. Kategorik değişkenler arasındaki ilişkilerin analizinde Pearson ki-kare testi kullanılmıştır. 0,05'den küçük p değerleri istatistiksel olarak anlamlı kabul edilmiştir. Analizler SPSS 18.0 paket programı ile yapılmıştır.

\section{BULGULAR}

Çalışmaya alınan 2.512 hastanın 876'sında (\%34,9) polip saptanırken $1.636(\% 65,1)$ hastada polip saptanmadı (Tablo 1). Polip saptanan hastalar histolojik olarak değerlendirildiğinde 104'ünde $(\% 11,9)$ hiperplastik polip saptanırken, 10 $(\% 1,1)$ hastada serrated polip, $650(\% 74,3)$ hastada adenomatöz polip saptandı. Adenomatöz polipler alt tiplerine göre saptanan tüm poliplere oranlandığında $585(\% 66,9)$ hastada tübüler, $57(\% 6,5)$ hastada tübülovillöz, $8(\% 0,9)$ hastada ise villöz adenom saptandı (Tablo 2). Boyuta göre 1 cm'den küçük ya da büyük olanlar sınıflandırıldığında saptanan poliplerin $696(\% 79,4)$ tanesi 1 cm'den küçükken, 180 (\%20,6) tanesi 1 cm'den büyük olarak saptandı (Tablo 3). Poliplerin yerleşim bölgeleri dikkate alındığında en sık rektal bölgede $323(\% 36,9)$ polip saptanırken, sıklık sırasına göre inen kolonda $150(\% 17,1)$, transvers kolonda $145(\% 16,6)$, sigmoid kolonda 131 (\%15), çıkan kolonda $69(\% 7,9)$ ve çekumda 57 $(\% 6,5)$ adet polip saptandı (Tablo 4).

\begin{tabular}{lcc} 
Tablo 2. Saptanan poliplerin patolojik durumu \\
\hline Patoloji & N & \% \\
Hiperplastik & 104 & 11,9 \\
Adenomatöz & & \\
$\quad$ Tübüler & 585 & 66,9 \\
$\quad$ Tübülovillöz & 57 & 6,5 \\
$\quad$ Villöz & 8 & 0,9 \\
Serrated & 10 & 1,1 \\
Adenokanser & 4 & 0,45 \\
Mukozal doku & 58 & 6,6 \\
Hamartamoz & 4 & 0,45 \\
NET & 2 & 0,2 \\
Lipom & 10 & 1,1 \\
Lenfoma & 2 & 0,2 \\
Inflamatuvar & 32 & 3,6 \\
\hline
\end{tabular}

NET: Nöroendokrin tümör

Tablo 3. Saptanan poliplerin boyutu

\begin{tabular}{|lcc|}
\hline Boyut & N & \% \\
\hline Küçük $1 \mathrm{~cm}$ & 696 & 79,4 \\
\hline Büyük $1 \mathrm{~cm}$ & 180 & 20,6 \\
\hline
\end{tabular}

Tablo 4. Saptanan poliplerin lokalizasyonu

$\begin{array}{lcc}\text { Lokalizasyon } & \mathbf{N} & \mathbf{\%} \\ \text { Rektum } & 324 & 36,9 \\ \text { Sigmoid } & 131 & 15 \\ \text { Inen kolon } & 150 & 17,1 \\ \text { Transvers kolon } & 145 & 16,6 \\ \text { Çıkan kolon } & 69 & 7,9 \\ \text { Çekum } & 57 & 6,5\end{array}$


Tablo 5. Demografik bilgiler ve polip özellikleri

\begin{tabular}{|c|c|c|c|c|c|c|}
\hline \multirow[b]{2}{*}{ Değişken } & & \multirow[b]{2}{*}{ Yaş } & \multicolumn{4}{|c|}{ Cinsiyet } \\
\hline & & & $\mathbf{p} \mathbf{X}^{2 \mathbf{P}}$ & Erkek & Kadın & $\mathbf{p} \mathbf{X}^{2 \mathbf{P}}$ \\
\hline \multirow{2}{*}{ Polip } & Var & $55,41 \pm 12,48$ & \multirow{2}{*}{$<0,001$} & 408 & 468 & \multirow{2}{*}{$<0,037$} \\
\hline & Yok & $50,37 \pm 13,91$ & & 655 & 985 & \\
\hline \multirow{2}{*}{ Histoloji } & Hiperplastik & $54,36 \pm 11,94$ & \multirow{2}{*}{0,010} & 50 & 54 & \multirow{2}{*}{0,714} \\
\hline & Adenomatöz & $58,59 \pm 12,56$ & & 299 & 351 & \\
\hline \multirow{2}{*}{ Boyut } & $<1 \mathrm{~cm}$ & $52,61 \pm 15,00$ & \multirow{2}{*}{0,043} & 345 & 351 & \multirow{2}{*}{0,024} \\
\hline & $>1 \mathrm{~cm}$ & $55,91 \pm 11,64$ & & 63 & 117 & \\
\hline
\end{tabular}

Hastaların demografik bilgileri ile polip varlığı, boyutu ve histolojisi karşılaştırıldığında polip saptanan hastaların yaşları $(55,41 \pm 12,48)$, polip saptanmayanlardan $(50,37 \pm 13,91)$ daha yüksek bulunmuştur ( $p<0,001)$. Cinsiyete göre polip varlığı değerlendirildiğinde erkeklerde polip saptanma oranı $(\% 38,5)$ kadınlardan $(\% 32,2)$ yüksektir $(\mathrm{p}=0,037)$ (Tablo 5). Adenomatöz polipli hastaların yaşı hiperplastik poliplilere göre daha düşük bulunmuştur $(p=0,01)$. Tam tersine cinsiyetin ise polip histolojisini etkilemediği istatistiksel olarak gösterilmiştir (p: 0.714) (Tablo 5). Polip boyutu 1 cm'den küçük ve büyük olan hastaların demografik sonuçlarına göre incelendiğinde 1 cm'den büyük polip boyutu olanların yaş ortalaması polip boyutu 1 cm'den küçük grubun yaş ortalamasından daha yüksektir ( $\mathrm{p}=0,043)$. Cinsiyete göre polip boyutu değerlendirildiğinde kadınlarda $1 \mathrm{~cm}$ 'den büyük polip görülme sıklığı erkeklere göre istatistiksel olarak anlamlı düzeyde daha fazla saptanmıştır ( $\mathrm{p}=0,024)$.

\section{TARTISSMA}

Türkiye'de kolorektal polipler ve kolorektal kanser yapılan çalışmalara göre incelendiğinde ABD ve Avrupa'daki sonuçlara göre daha az sıklıkta görülmektedir ve bunun en önemli nedeni tarama programlarındaki tıbbi eksiklikler ve hasta bazlı uyumsuzluklardır. Aynı zamanda ülkemizde kolon polip prevalansını belirleyecek çapta geniş bir çalışma henüz mevcut değildir. Mevcut çalışmalarda ortalama \%20-25 civarinda kolon polip prevalansı olduğunu görmekteyiz (9-10). Çalışmamızda saptadığımız \%34,9'luk polip görülme sıklığı ise Avrupa ve Amerika'da yapılan birçok çalışma sonucuna benzerlik göstermektedir. Bu noktada tarama programlarına verilmesi gereken önem bir kez daha ön plana çıkmaktadır. Erkeklerde kolon polip görüşme sıklığının kadınlara göre 2-3 kat daha fazla olduğunu gösteren çalışmalar mevcut olup çalışmamızda da erkeklerde kolon polibi istatistiksel olarak anlamlı düzeyde fazla saptanmıştır fakat bu aradaki fark literatürdeki veriler kadar fazla değildir (11).

Poliplerin histolojik özellikleri malignite gelişimi açısından en önemli basamağı oluşturmakta olup literatürde genel olarak adenomatöz polip görülme sıklığının hiperplastik poliplere göre 4-5 kat daha fazla olduğunu görmekteyiz. Shinya ve arkadaşlarının yaptığı çalışmada tespit edilen poliplerin $\% 75$ 'i adenomatöz ve \%25'i hiperplastiktir (1). Çalışmamızda ise adenomatöz polipler $\% 74,3$, hiperplastik polipler ise \%11,9 oran ile literatüre paralellik göstermektedir. Literatürün aksine Italya'da yapılan bir çalışmada ise sıkı Akdeniz diyeti ile beslenen 314 kişinin poliplerinin histolojisi incelenmiş ve adenomatöz poliplerin sadece 1,5 kat daha sık görüldüğü saptanmıştır (12). Bu noktada özellikle Akdeniz tipi beslenmenin polip gelişimi açısından koruyucu olabileceği düşünülmekle birlikte konu hakkında ayrıntılı çalışmalara ihtiyaç vardır. Çalışmamızda kolorektal adenomatöz polipleri hiperplastik poliplerden 6 kat daha sık saptadığımız düşünüldüğünde bu durumun literatür ile uyumlu olduğu düşünülebilmektedir. Tübüler adenomlar adenomatöz poliplerin \%80-86'sını, villöz adenomlar \%3-16'sını, tübülovillöz adenomlar \%8-16'sını oluştururlar (13). Çalışmamızda saptadığımız histoloji sonuçları tübüler ve tübülövillöz adenomlar açısından literatürle uyumlu olmakla birlikte villöz adenomları literatüre göre daha az sayıda saptadığımızı görmekteyiz. Yaşla birlikte istatistiksel anlamlı düzeyde adenomatöz polip gelişiminde artış olması özellikle kolon kanserinin de ilerleyen yaşla birlikte görülme sıklığının arttığı düşünüldüğünde artan adenomatöz polip sıklığının bu duruma öncülük etmesi beklenen bir bulgudur. Hastaların yaş ortalaması açısından literatür incelendiğinde erkeklerde 53-59 yaş, kadınlarda 4046 yaş ve genel yaş ortalaması 43-61 arasında değişmektedir (14). Çalışmamızda erkekler için yaş ortalaması literatür ile uyumlu olmakla birlikte kadinlarda kolon poliplerini daha geç yaşlarda saptadığımızı görmekteyiz. Özellikle anemi etiyolojisi araştırılırken fertil dönemdeki kadınlarda menstruasyon döngüsüne bağlı olarak kolonoskopik araştırmaların geciktirilmesine bağlı kolon poliplerini daha geç yaşlarda saptamış olabileceğimizi düşünmekteyiz.

Malignite gelişimi açısından bir diğer önemli parametre olan polip boyutu incelendiğinde bu konuda literatürde yapılmış çalışma sayısı kısıtlıdır. Polipler genel olarak 1 cm'den küçük olmakla birlikte hastanın yaşı ve polibin kolonda bulundugu lokalizasyonu polip boyutunu etkileyen parametrelerdir. Otopsi çalışmalarına göre polipler genel olarak \%10-15 oranında 1 cm'den büyüktür (15). Kolon yerleşimi olarak ba- 
kıldığında ise özellikle proksimale ilerledikçe ortalama polip boyutlarında artış göze çarpmaktadır (15). Çalışmamızda ise 1 cm'den büyük polip görülme sıklığı \%20 olarak saptanmış olup literatüre göre daha sık 1 cm'den büyük polip saptadığımız görülmektedir. Beklenildiği gibi 1 cm'den büyük polibi olan hastaların yaş ortalaması istatistiksel olarak anlamdı düzeyde daha yüksektir. Buna ek olarak erkek cinsiyet de 1 cm'den büyük polip gelişimini artıran bir veri olarak saptanmiştır.

Lokalizasyon açısından değerlendirildiğinde kolorektal polipler distal kolon ve rektumda daha sık görülürler. Küçük polipler için belirli bir lokalizasyon söylemek mümkün değilken, büyük polipler daha sik distal kolon yerleşimlidir $(7,8)$. Kolon polipleri anatomik olarak \%40 oranında sağ kolon yerleşimli iken (çekum, çıkan kolon, hepatik fleksura, transvers kolon) \%31 sol kolon yerleşimli (splenik fleksura, inen kolon ve sigmoid kolon) ve \%29 oraninda rektum yerleşimlidir. 1980'den bu yana kolon kanserleri sol kolondan sağa doğru değişim göstermektedir (8). Saptadığımız polip-

\section{KAYNAKLAR}

1. Shinya H, Wolff WI. Morphology, anatomic distribution and cancer potential of colonic polyps. Ann Surg 1979;190:679-83

2. Edwards BK, Ward E, Kohler BA, et al. Annual report to the nation on the status of cancer, 1975-2006, featuring colorectal cancer trends and impact of interventions (risk factors, screening, and treatment) to reduce future rates. Cancer 2010;116:544-73.

3. Armstrong B, Doll R. Environmental factors and cancer incidence and mortality in different countries, with special reference to dietary practices. Int J Cancer 1975; 15:617-31.

4. Locke FB, King H. Cancer mortality risk among Japanese in the United States. J Natl Cancer Inst 1980;65:1149-56.

5. Honda T, Kai I, Ohi G. Fat and dietary fiber intake and colon cancer mortality: a chronological comparison between Japan and the United States. Nutr Cancer 1999;33:95-9.

6. O'Brien MJ, Winawer SJ, Zauber AG, et al; National Polyp Study Workgroup. Flat adenomas in the National Polyp Study: is there increased risk for high-grade dysplasia initially or during surveillance? Clin Gastroenterol Hepatol 2004;2:905-11.

7. Schatzkin A, Lanza E, Corle D et al. Lack of effect of a low-fat, high fiber diet on the recurrence of colorectal adenomas. New Eng J Med 2000;342:1149-55

8. Jass JR, Subsite distribution and incidence of colorectal cancer in New Zealand, 1974-1983. Dis Colon Rectum 1991;34:56-9.

9. Eminler AT, Sakallı M, Irak K, et al. Colonoscopic polypectomy results of our gastroenterology unit. Akademik Gastroenteroloji Dergisi 2011;10:112-5 ler lokalizasyon açısından değerlendirildiğinde literatürle uyumlu bir şekilde en sik rektal bölgede $323(\% 36,9)$ polip saptanırken, siklık sirasına göre inen kolonda 150 (\%17,1), transvers kolonda 145 (\%16,6), sigmoid kolonda 131 (\%15), çıkan kolonda $69(\% 7,9)$ ve çekumda $57(\% 6,5)$ adet polip saptanmıştır. Sol kolonda görülen polip yüzdesinde artış olduğunu saptayan yeni dönem çalışmalar ile karşılaştırıldı ̆̆ında sol kolonda görülen polip yüzdemizin düşük kaldığı ve sol kolon polip görülme yüzdelerimizin literatürdeki eski dönem çalışmalar ile uyumlu olduğu görülmüştür $(16,17)$.

Sonuç olarak çalışmamızda kolonoskopi ile saptanan poliplerin prevalans, histoloji, boyut ve lokalizasyonu ile ilgili epidemiyolojik bilgiler edinildi. Literatür verilerine göre saptadığımız yüksek polip prevalansı tarama programlarında daha dikkatli davranmamız gerektiğini düşündürmüştür. Bununla birlikte her ne kadar sol kolon poliplerinin prevalansında artış saptamamış olsak da boyut ve histolojik özellikleri kanser gelişimine daha yatkın olduğu için endoskopik incelemelerde tüm kolonun ayrıntılı değerlendirmesi son derece önemlidir.

10. Dölek Y, Yuyucu Karabulut Y, Topal F, Kurşun N. Evaluation of gastrointestinal polyps according to their size, localization and histopathologic types. Endoskopi Dergisi 2013;21:31-5.

11. Bond JH. Polyp guideline: diagnosis, treatment, and surveillance for patients with colorectal polyps. Practice Parameters Committee of the American College of Gastroenterology. Am J Gastroenterol 2000;95:305363.

12. Bingham SA, Day NE, Luben R. et al; European Prospective Investigation into Cancer and Nutrition. Dietary fibre in food and protection against colorectal cancer in the European Prospective Investigation into Cancer and Nutrition (EPIC): an observational study. Lancet 2003;361:1496501.

13. Terry MB, Neugut AI, Bostick RM, et al. Risk factors for advanced colorectal adenomas a pooled analysis. Cancer Epidemiol Biomarkers Prev 2002;11:622-9.

14. Giovannucci E. Epidemiologic studies of folate and colorectal neoplasia: a review. J Nutr 2002;132(8 Suppl):2350S-5S

15. Morson B. Polyp-cancer sequence in large bowel. Proc R Soc Med 1974;67:451-7.

16. Hoff G, Foerster A, Vatn MH, et al. Epidemiology of polyps in the rectum and colon: recovery and evaluation of unresected polyps 2 years after detection. Scand J Gastroenterol 1986;21:853-62.

17. Pooler BD, Kim DH, Weiss JM, et al. Colorectal polyps missed with optical colonoscopy despite previous detection and localization with CT colonography. Radiology 2016;278:422-9. 